\title{
Simulation of a ship operating in an open-water ice channel
}

$$
\text { Luofeng Huang }{ }^{\mathrm{a},} \text { *, Minghao Li }{ }^{\mathrm{b}} \text {, Tuomas Romu }{ }^{\mathrm{c}}, \text { Azam Dolatshah }^{\mathrm{d}}, \text { Giles Thomas }{ }^{\mathrm{a}}
$$

(1)

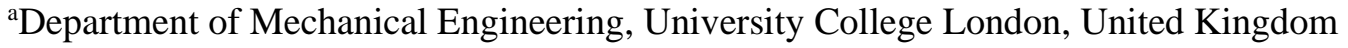 \\ ${ }^{b}$ Department of Mechanics and Maritime Science, Chalmers University of Technology, Sweden \\ ${ }^{\mathrm{c} A k e r}$ Arctic Technology Inc, Finland \\ ${ }^{\mathrm{d}}$ Faculty of Science, Engineering and Technology, Swinburne University of Technology, Australia
}

\begin{abstract}
Modern ice breakers, using new technology, are now able to create channels through level ice and clean out the ice fragments, resulting in an open-water channel between two large ice sheets. Whilst this negates the potential resistance increase on a following vessel due to interacting with the broken ice pieces, the ship performance will still be influenced by the two large ice sheets on either side. The effect of such ice sheets on ships has to date not been studied in detail, so the channel effect is usually ignored during ship design processes and power estimates. The climate change provides an increasing impetus for large-scale Arctic shipping that will involve ice channels. Motivated by the status quo, the present paper reports on work to develop a computational model to simulate a ship advancing in an open-water ice channel and investigate the associated ship-wave-ice interaction. Based on a series of simulations, the existence of ice sheets is demonstrated to reflect the ship wake and thereby increase the ship resistance, and this work subsequently analyses the relationship of the resistance increment with ship speed, channel width and ice thickness. When the channel dimension is similar to a practical situation, the ship-wave-ice interaction is evident and considerably increases the ship resistance. This suggests the importance of appropriately accounting for the channel effect in future polar engineering.
\end{abstract}

Keywords: Ship; Ice channel; Wave; Resistance; Computational Fluid Dynamics. 


\section{Introduction}

In regions where sea ice develops, commercial ships usually request icebreakers to create channels to enable them to safely reach their destination. The ice-breaking process used to result in a channel full of ice fragments, known as a brash ice channel, as shown in Figure 1(a). The brash ice channel is a traditional scenario of Arctic shipping, and studies have been widely conducted to predict the ship resistance induced by the brash ice (Kitazawa \& Ettema 1985; Konno et al. 2011; Konno et al. 2013; Jeong et al. 2017; Mucha 2019). The total ship resistance in a brash ice channel is normally split between the larger component for moving against the ice fragments $\left(\mathrm{R}_{\mathrm{ice}}\right)$, and the smaller calm water ship resistance ( $R_{\text {water }}$ ). Then the total resistance of the ship can be expressed as $R_{\text {total }}=R_{\text {ice }}+R_{\text {water }}$. Kitazawa and Ettema (1985) compared model tests of ships operating in brash ice channels with in open water, and found that $R_{\text {ice }}$ can be several times greater than $R_{\text {water }}$, also concluding that $R_{\text {ice }}$ is almost linearly proportional to the thickness of the brash-ice layer.

Since the resistance increment induced on ships operating in ice channels by brash ice is significant, various techniques have been developed for modern icebreakers to clean the broken ice fragments produced during the ice-breaking process. One such method is turning the azimuth-propulsion units inwards by 15 30 degrees, called "toe-in" mode, with which the flushing effect can push the broken ice pieces under the ice sheets, thus cleaning the channel and make it slightly wider. Such technology is effective for reducing the brash ice resistance component, as well as reducing the likelihood of blockages in the new channel due to freezing of the broken ice pieces (Koskinen \& Savikurki 1993). This approach therefore results in an open water channel between two large ice sheets, as shown in Figure 1(b), an operational environment for shipping in cold climates that will increase in likelihood. Particularly, with the climate change in the Arctic that involves ice reduction in both extent and thickness (Stroeve et al. 2012; Laxon et al. 2013), new shipping routes are opening and vast quantities of natural resources such as oil, gas and minerals are becoming extractible (Smith \& Stephenson 2013; Wadhams 2017), and yet in the first half of $21^{\text {st }}$ century the shipping season will remain variable and unreliable, continuing to require ice-breaker escort (Melia et al. 2017). Large-scale ship operations in such ice channels are expected, with which the importance of studying this case is raising.

To date, limited research into ship performance in open-water ice channels has been conducted, with few experimental investigations found on this scenario. Leiviska et al. (2001) conducted model tests of an oil tanker with a range of open-water ice channels of different ice thicknesses and channel widths. The original purpose of their work was to identify the effect of a brash ice channel on ship resistance, as the authors proposed that $R_{\text {water }}$ would be influenced by the characteristics of the ice channel and therefore cannot be a standalone term in the resistance expression, i.e. both $R_{\text {ice }}$ and $R_{w a t e r}$ should change with channel parameters, rather than only $\mathrm{R}_{\text {ice. }}$ In their results, an open-water ice channel was seen to induce a markedly higher resistance than that of a pure open-water situation without any ice, and the 


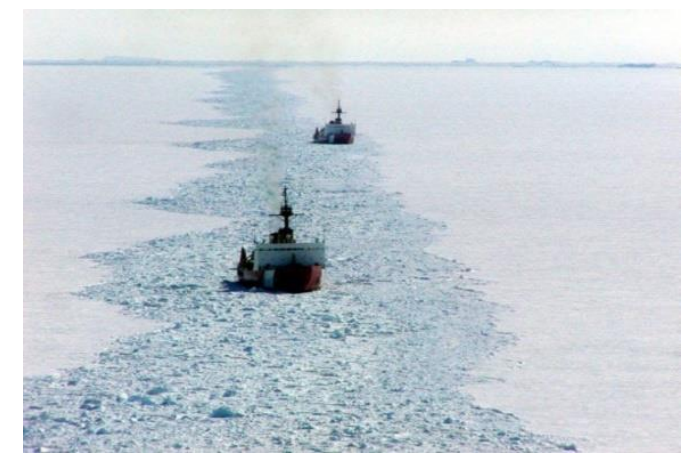

(a) Brash ice channel (credit: US Coast Guard) resistance changes with environmental parameters. resistance increment was found to be influenced by channel width and ship speed. Particularly, the resistance increments are evident when the channel width is less than three times of the ship. Heinonen (2010) reported on model tests for an icebreaker in open-water ice channels and also observed that the close proximity of the ice edge to the ship can increase the resistance. However, both Leiviska et al. (2001) and Heinonen (2010) claimed that more studies are required to clarify the mechanism behind.

Since conducting experiments for this operational scenario in ice is prohibitively complex and expensive, there is a need to have an accurate and reliable approach to numerically simulating the situation. This work will use the Computational Fluid Dynamics (CFD) method to gain insights into the ship-wave-ice interaction, since this method has been shown to be valid for similar applications, e.g. ship operation in a canal (Mucha et al. 2016). CFD is able to obtain the wave patterns within a channel and break down the ship resistance into pressure and shear components, based on which it is promising to shed light on why the resistance is different in an ice channel. In the remainder of this paper, a set of CFD approach will be introduced along with concomitant simulations considering different ship speeds and channel dimensions. Benefitting from the post-processing capability of CFD, the ship-wave-ice interaction is presented in detail, based on which this paper demonstrates why and how the ship

Figure 1: Icebreaker-created channels for commercial ships to navigate.

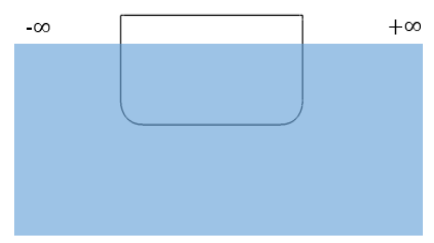

(a) Open ocean

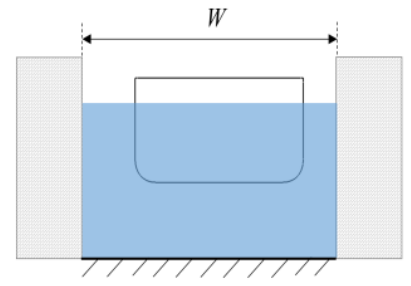

(b) Canal

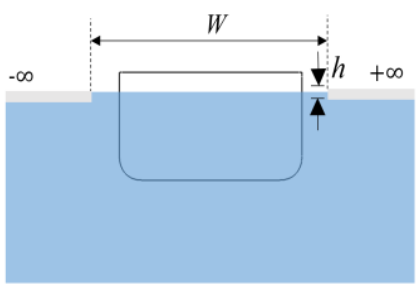

(c) Open-water ice channel

Figure 2: Comparison of ship operating in three different scenarios: open ocean, canal and openwater ice channel; $W$ is the width of the channel and $h$ is the ice thickness. 


\section{Numerical approach}

CFD has been successfully applied to predict ship performance in a similar scenario with a restricted waterway, i.e. when operating in a canal, with good agreement obtained with experiments (Mucha \& Moctar 2014; Mucha et al. 2016; Tezdogan et al. 2016; Terziev et al. 2018). Even so, despite the similarities between a canal and an open-water ice channel, there are certain important differences between these two cases. Figure 2 provides a schematic comparison of a ship operating in open water, a canal and an open-water ice channel. The proposed problem is different from a canal as the ice has a limited thickness and is floating on the water surface. In addition, the water depth in a canal is usually restricted, thus limiting underkeel clearance, while an ice channel tends to be in deep water. Considering these differences, this work employed similar theories that used for the canal case, while applying the ice-channel geometry to confine the ship.

\subsection{Ship model and fluid domain}

The KRISO Container Ship (KCS), was adopted as the ship model in this study. KCS is a typical container ship model applied to computational simulations, as its geometry with abundant measurement data can be found in the public domain (Kim et al. 2001). It is designed as an open-water vessel while such ships regularly operate in ice channels with icebreaker assistance. The length of this hull is $230 \mathrm{~m}$ at full-scale with a scale ratio of 1:52.667 applied in this study, resulting in a model length $\mathrm{L}_{\mathrm{pp}}=4.367$ $\mathrm{m}$, breadth $\mathrm{B}=0.611 \mathrm{~m}$ and draught $\mathrm{T}=0.205 \mathrm{~m}$. The hull parameters are summarised in Table 1 .

Table 1. Main dimensions of the KCS hull.

\begin{tabular}{l||ll}
\hline & Model scale & Full scale \\
\hline Length between perpendiculars (m) & 4.367 & 230.0 \\
Waterline breadth (m) & 0.611 & 32.2 \\
Draught midships (m) & 0.205 & 10.8 \\
Trim angle (rad) & 0.0 & 0.0 \\
Block coefficient (-) & 0.651 & 0.651 \\
Wetted surface $\left(\mathrm{m}^{2}\right)$ & 3.397 & 9424.0 \\
\hline
\end{tabular}




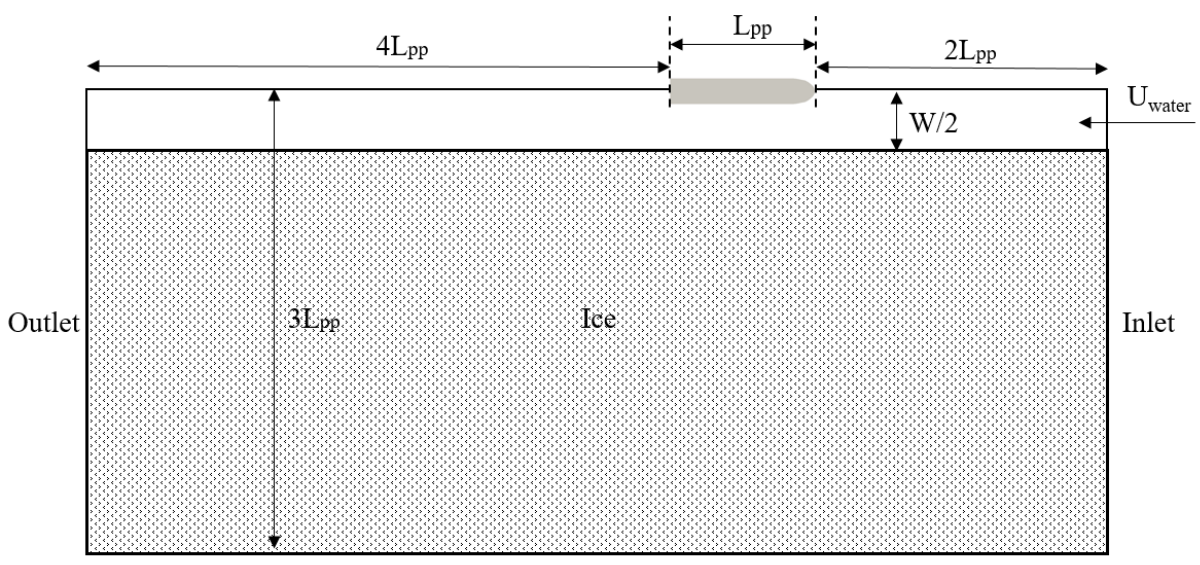

(a) plan view

(b) section view.

Figure 3: Sketch of the computational domain

114 A three-dimensional computational domain was established using the Star-CCM+ software, as 115 illustrated in Figure 3, and the domain size is sufficiently large to model an ocean condition (Huang et 116 al. 2019a; Huang et al. 2019b). The lower part of the domain is filled with water and the remainder is 117 filled with air. The hull is fixed across the waterline according to its design draught. On each side of the 118 ship, an ice sheet is placed at a distance ( $2 / W$, where $W$ denotes the channel width) from the ship central 119 line, with $90 \%$ of ice thickness ( $h$ ) immersed in water (assuming ice density equals to $900 \mathrm{~kg} / \mathrm{m}^{3}$ ). The water was initialised as flowing with a uniform velocity $\left(U_{\text {water }}\right)$ against the bow of the hull, and a 121 constant velocity condition is applied to the inlet boundary to maintain a stable water flow entering the 122 domain. The same initial and boundary velocity was also applied to the ice surfaces. Thus, a relative 123 velocity exists between the ship and water/ice, where $U_{\text {water }}$ indicates the advancing speed of the ship in 
calm water. The ship speed may be converted to Froude number Fr $=U_{\text {water }} / \sqrt{g \times L_{p p}}$, where $g$ and $L_{p p}$ are gravitational acceleration and ship length respectively. The ship surface and ice surface are defined as non-slip walls, and the fixed-dynamic-pressure condition is applied to the outlet, with the zero-gradient condition applied to other boundaries.

\subsection{Governing equations}

The solution of the fluid domain was obtained by solving the Reynolds-Averaged Navier-Stokes (RANS) equations for an incompressible Newtonian fluid:

$$
\begin{gathered}
\nabla \cdot \overline{\mathbf{v}}=0 \\
\frac{\partial(\rho \overline{\mathbf{v}})}{\partial t}+\nabla \cdot(\rho \overline{\mathbf{v}})=-\nabla \bar{p}+\nabla \cdot\left(\bar{\tau}-\rho \overline{\mathbf{v}^{\prime} \mathbf{v}^{\prime}}\right)+\rho g
\end{gathered}
$$

where $\overline{\mathbf{v}}$ is the time-averaged velocity, $\mathbf{v}^{\prime}$ is the velocity fluctuations, $\rho$ stands for the density, $\bar{p}$ denotes the time-averaged pressure, $\bar{\tau}=\mu\left[\nabla \mathrm{v}+(\nabla \mathrm{v})^{\mathrm{T}}\right]$ is the viscous stress term, $\mu$ is the dynamic viscosity and $g$ is gravitational acceleration set at $9.81 \mathrm{~m} / \mathrm{s}^{2}$. Since the RANS equations have considered the turbulent fluid, the Shear Stress Transport (SST) k - $\omega$ model (Menter 1993) was adopted to close the equations. The SST k - $\omega$ model has been proposed to be the most appropriate option among standard RANS turbulence models for predicting the flow field around a ship hull (Zhang et al. 2006).

The free surface between the air and water was modelled by the Volume of Fluid (VOF) method (Hirt $\&$ Nichols 1981). The VOF method introduces a passive scalar $\alpha$, denoting the fractional volume of a cell occupied by a specific phase. In this case, a value of $\alpha=1$ corresponds to a cell full of water and a value of $\alpha=0$ indicates a cell full of air. Thus, the free surface, which is a mix of these two phases, is formed by the cells with $0<\alpha<1$. The elevation of the free surface along time is obtained by the advection equation of $\alpha$, expressed as Equation (3). For a cell containing both air and water, its density and viscosity are determined by a linear average according to Equation (4) and Equation (5). In this study, $\rho_{\text {water }}=998.8 \mathrm{~kg} / \mathrm{m}^{3}, \mu_{\text {water }}=8.90 \times 10^{-4} \mathrm{~N} \cdot \mathrm{s} / \mathrm{m}^{2} ; \rho_{\text {air }}=1 \mathrm{~kg} / \mathrm{m}^{3}, \mu_{\text {air }}=1.48 \times 10^{-5} \mathrm{~N} \cdot \mathrm{s} / \mathrm{m}^{2}$.

$$
\begin{gathered}
\frac{\partial \alpha}{\partial t}+\nabla \cdot(\overline{\mathbf{v}} \alpha)=0 \\
\rho=\alpha \rho_{\text {water }}+(1-\alpha) \rho_{\text {air }} \\
\mu=\alpha \mu_{\text {water }}+(1-\alpha) \mu_{\text {air }}
\end{gathered}
$$




\subsection{Computational method}

The governing equations of the fluid domain were discretised and solved using the Finite Volume method (Versteeg \& Malalasekera 2007). The process includes two types of discretization, in space and time, respectively. In space, the computational domain is divided into a set of non-overlapping cells, known as a mesh; in time, the temporal dimension is split into a finite number of timesteps. For a single timestep, the solution of the governing equations can be obtained in each cell (e.g., $v ; \mathrm{P} ; a$ ) and the solution of the whole domain can be integrated by the solution of all cells. Subsequently, the solution over a certain time duration is the composition of the solution at each timestep.

In this study, the computational domain was divided into a hexahedral mesh, and local mesh refinements were applied at the free-surface area and around the ship and ice sheets, as shown in Figure 4, resulting in a cell number of around 10.8 million. Five layers of cells are applied at the ship and ice surfaces so that the boundary layer can be properly solved, shown in Figure 4(b) and (c). The size of each timestep was determined by a prescribed value, Courant number (Co), according to Co $=\frac{\mathrm{u} \Delta \mathrm{t}}{\Delta \mathrm{x}}<1$, where $\Delta \mathrm{t}$ is the timestep size, $\mathrm{u} / \Delta \mathrm{x}$ is its normal velocity divided by the distance between the cell centre and the centre of the neighbour cell. Based on Co $<1$, the time-step size is set at $0.01 \mathrm{~s}$ in this study. Both the mesh and timestep resolutions were justified through verification studies presented in the next section.

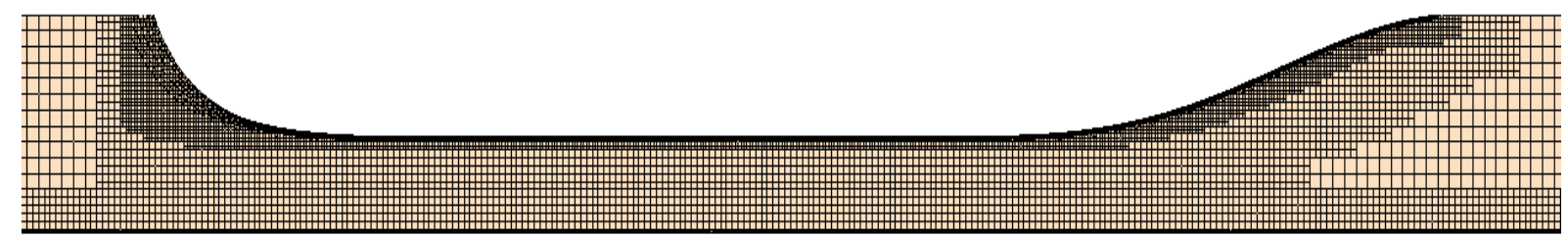

(a) Plan view of half channel

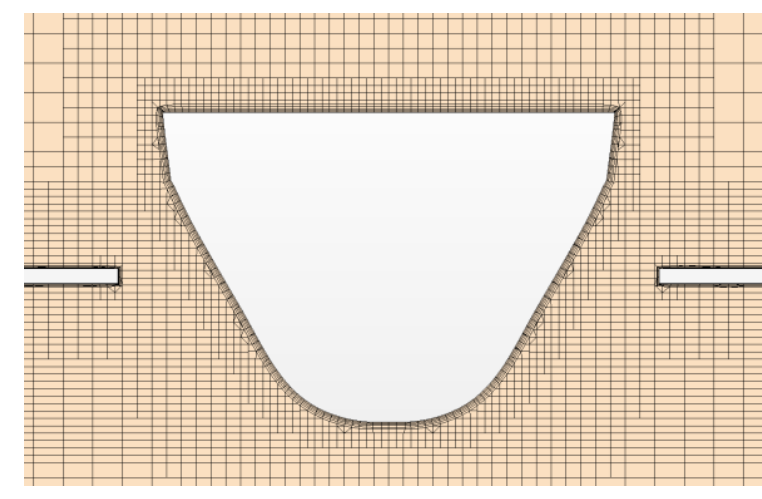

(b) Section view

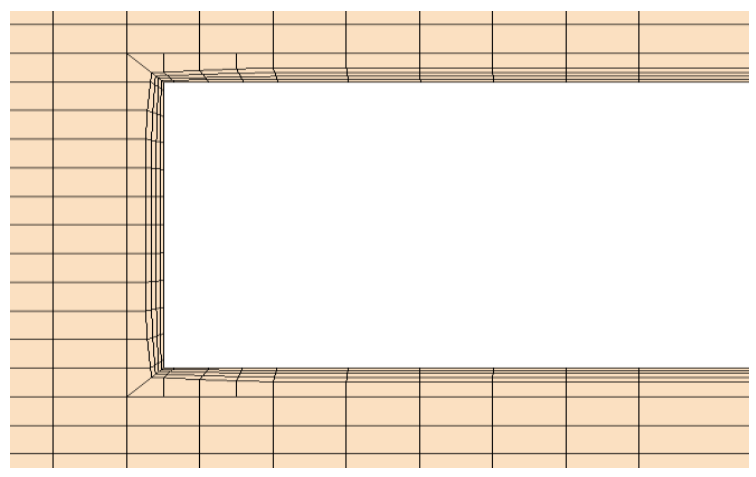

(c) Close-up section view at the ice edge

Figure 4: Mesh layout of the model 


\section{Results and discussion}

171 When a ship is advancing in an open-water ice channel, it generates waves which can be reflected due to the presence of ice, as shown in Figure 5; when the channel width, relative to the ship's beam $(W / B)$,

173 changes, the wave pattern evolves accordingly. In addition, certain wake is observed flowing on top of 174 the ice, known as overwash (Skene et al. 2015; Huang \& Thomas 2019). The changed flow leads to different ship hydrodynamics compared to the open-water case. It can be seen that when W/B $>2.5$, the channel barely influences the wave pattern; in such a scenario, the ship resistance is very close to measured in open water. These resistance values are aligned with corresponding experimental data (Guo et al. 2018), compared in Figure 6, which indicates the applied approach is valid. Whilst similar CFD methods have been validated for the canal case (Mucha et al. 2016), there is a lack of experimental data for the exact ice channel scenario, therefore extensive verification is essential to justify the proposed approach.

(a) $\mathrm{W} / \mathrm{B}=1.2$
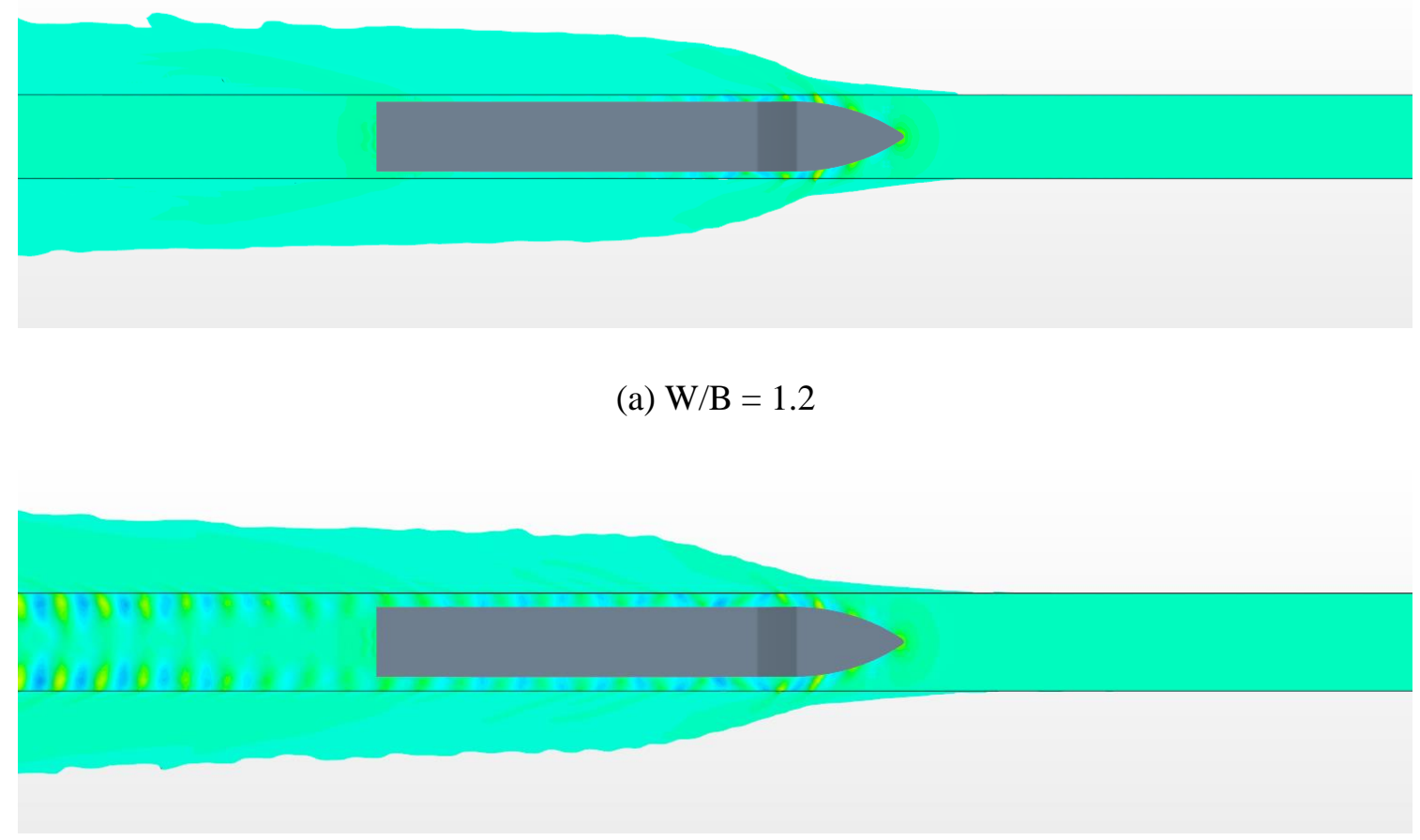

(b) $\mathrm{W} / \mathrm{B}=1.4$

(c) $\mathrm{W} / \mathrm{B}=1.6$ 
(d) $\mathrm{W} / \mathrm{B}=1.8$

191

(e) $W / B=2$

193
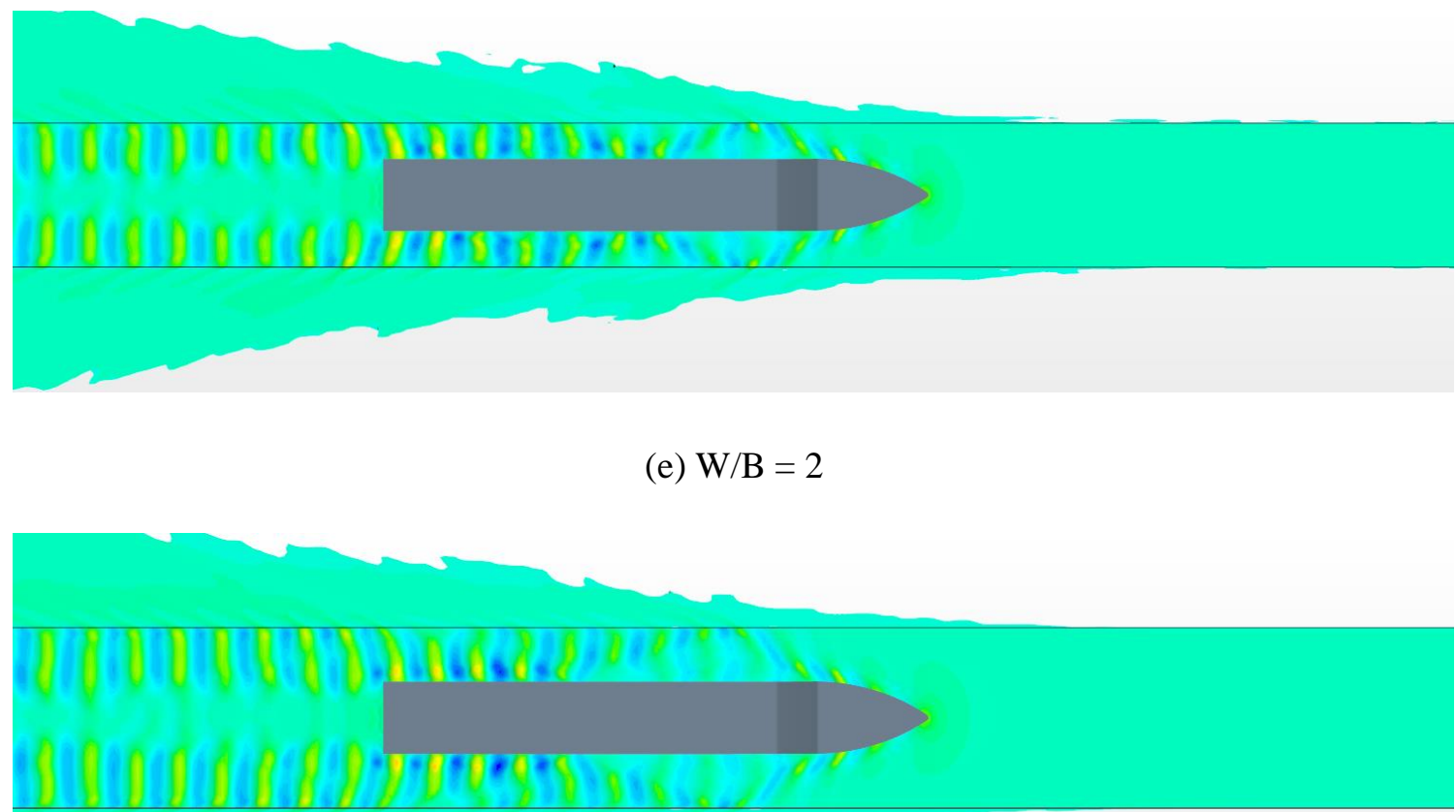

\section{3}

(f) $\mathrm{W} / \mathrm{B}=2.5$

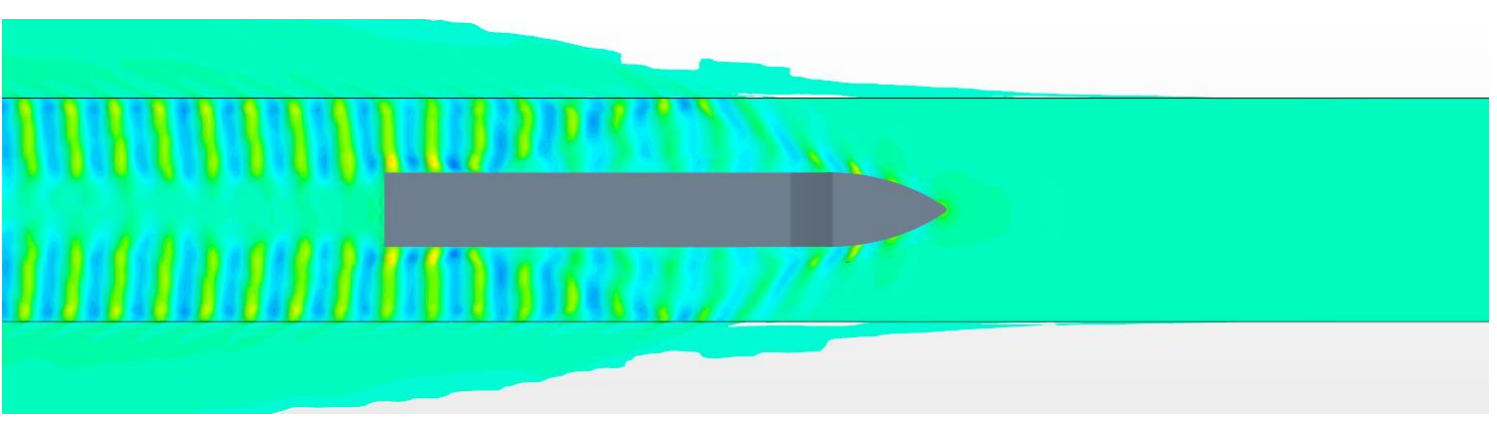

(g) W/B = 3 


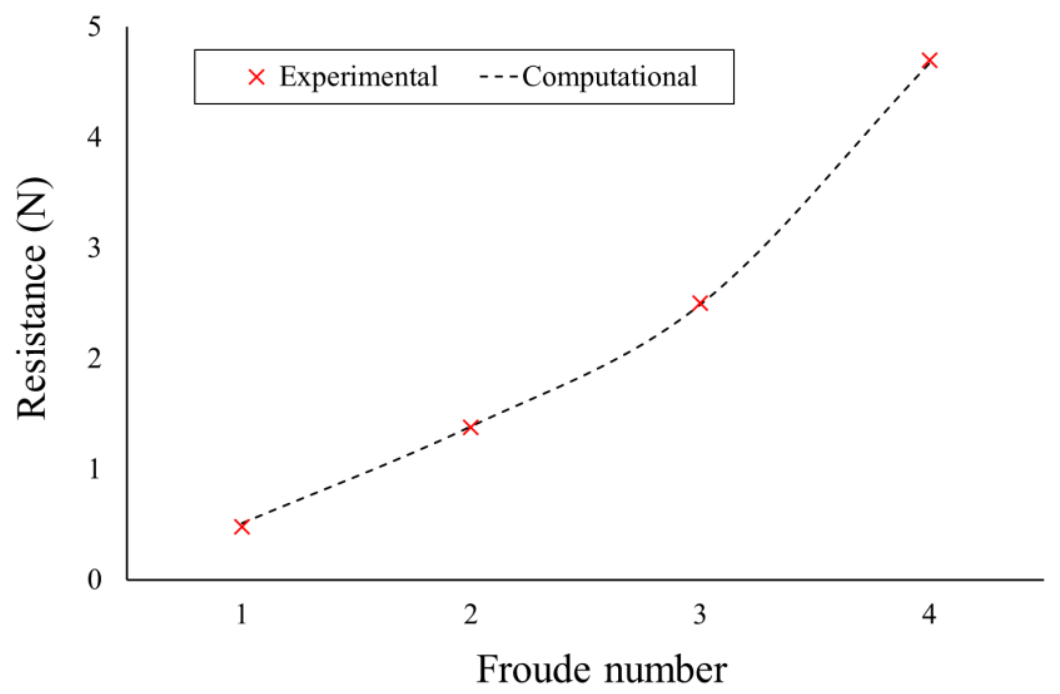

Figure 6: Experimental (Guo et al. 2018) and computational resistance of the KCS hull in modelscale, in open water or when W/B $>2.5$.

Numerical verifications in hydrodynamics usually only examine integral quantities (e.g. ship resistance), while Phillips and Roy (2016) proposed a procedure of verifying local quantities (e.g. free surface elevation). This has inspired the present work to include a verification study on the free surface between the ice sheets, since the ice-affected wake is a key feature of the present problem and governs the associated hydrodynamics. According to the standard verification procedure of the International Towing Tank Conference (ITTC 2017), a representative case is first adopted, and then simulations are performed for the same case with different levels of temporal and spatial discretisation. The representative case selected in the current work is: $\mathrm{W} / \mathrm{B}=1.2, h / \mathrm{T}=0.1$, and $\mathrm{Fr}=0.03$. This case is for the slowest speed examined, combined with a channel whose width and ice thickness are able to produce significant wave reflections. The representative case is found to be the most challenging in the present study; in other words, this case requires the highest numerical accuracy so its verification can be reasonably adapted to other simulation conditions.

Based on the representative case, the timestep and mesh sizes were systematically varied, resulting in four sets of resolutions for temporal and spatial respectively, listed in Table 2 as Tests 1-7, alongside their corresponding resistance results. With different timestep sizes, the resistance is shown to be insensitive despite the simulation gets divergent when the timestep size is increased to $0.028 \mathrm{~s}$. On the other hand, the resistance shows a monotonic convergence (Celik et al. 2008) with the tested mesh densities; it gradually approaches a certain value and the variance is not significant when the cell number is larger than 10.8 Million. 
Another verification was performed for the free surface in the channel. Figure 7 presents the obtained free surface of the tests in Table 2. Comparing Figure 7 (a)-(c), it is worth noting that the larger timestep sizes (Test 2 and 3) produce oscillating free surfaces even in front of the ship, which is unrealistic and suggests the boundary conditions cannot be precisely implemented using the applied resolutions. However, the resistance values of Test 1-3 are similar, as reported in Table 2. This confirms the importance of verifying free surface; even if integral quantities (resistance) achieve convergent, localised divergences can still exist. In this channel case, it is particularly related to the demanding requirement of solving the small clearance between the ship and ice. Figure 7 (a), (d) and (e) reveal the mesh convergence aligned with the resistance results, and Figure (f) shows inferior free surfaces due to bad mesh quality. Based on the sensitivity studies on both resistance and free surface, the resolution of Test 1 is selected to perform further simulations.

Table 2. Ship resistance with varying discretisation resolutions

\begin{tabular}{ccc||c}
\hline Test number & Timestep size (s) & Cell number & Resistance (N) \\
\hline 1 & 0.01 & 10.8 Million & 0.514 \\
2 & 0.014 & 10.8 Million & 0.512 \\
3 & 0.02 & 10.8 Million & 0.505 \\
4 & 0.028 & 10.8 Million & divergent \\
5 & 0.01 & 14.9 Million & 0.524 \\
6 & 0.01 & 7.6 Million & 0.485 \\
7 & 0.01 & 5.4 Million & 0.414 \\
\hline
\end{tabular}

(a) Test 1

(b) Test 2 
(c) Test 3

(d) Test 5

246

(e) Test 6

(f) Test 7

Figure 7: Free surface obtained with varying discretisation resolutions.

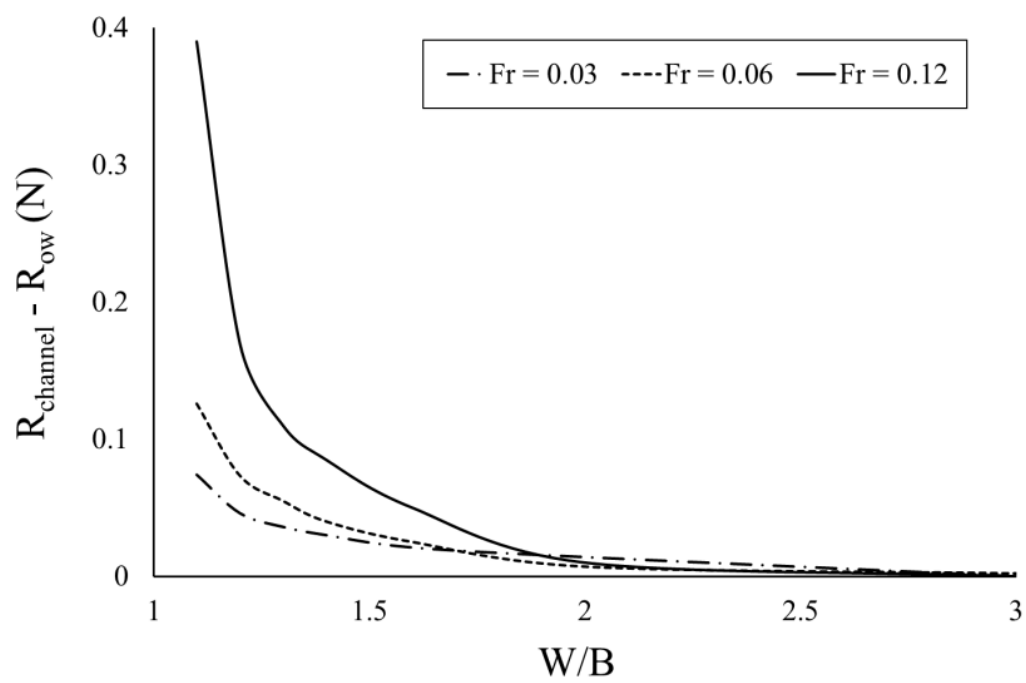

(a) Absolute increment 


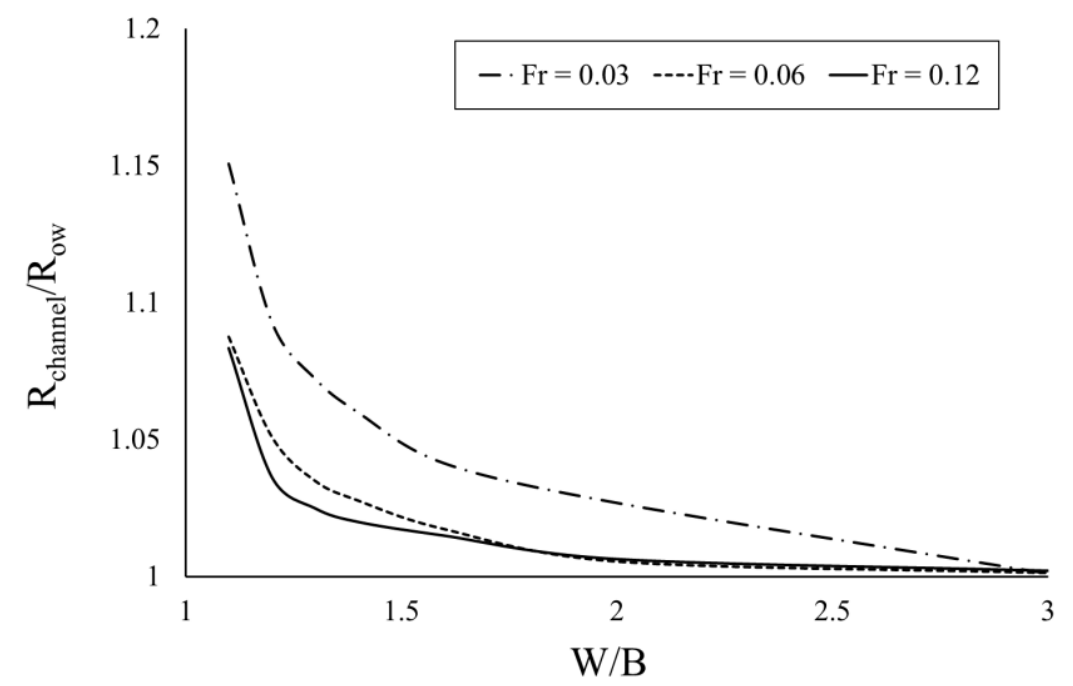

254

\subsection{Ship resistance}

A series of simulations were conducted to predict the ship resistance in an open-water ice channel and determine how it is influenced by ship speed, channel width and ice thickness. Figure 8 presents the ship resistance for varying ship speeds and channel widths, which is compared with the open water resistance to distinguish the channel effect, including two subfigures respectively showing the absolute change $\left(R_{\text {channel }}-R_{\text {ow }}\right)$ and relative change $\left(R_{\text {channel }} / R_{\text {ow }}\right)$. In accordance with the changing of wave pattern, the presence of the channel starts to influence the ship resistance when W/B $<2.5$, which is in line with practice as an icebreaker normally cannot create a channel wider than this range. On the other hand, this limit is much lower than that of a canal case (Gourlay et al. 2015; Mucha et al. 2018), as the ice is of limited thickness and the water is not shallow. Overall, the resistance increases with a decreased channel width.

Figure 8(a) shows the absolute resistance increment is larger for a larger ship velocity, which is not surprising as larger wave reflections occurring. In contrast, Figure 8(b) illustrates that the relative resistance increment is larger for the low-velocity condition $(\mathrm{Fr}=0.03)$, indicating the channel effect is more influential when the ship is operating slowly, which agrees with the experiments of both Leiviska et al. (2001) and Heinonen (2010). It means that, with increasing ship speed, the channel-added resistance increases more slowly than the basic open-water resistance, thus the relative change becomes smaller. This characteristic can be important as ships usually operate slowly in such ice channels.

To analyse the reason for such resistance changes, pressure and shear components of the resistance are split in Table 3. It shows that the resistance change is mainly attributed to the pressure component. Such 
significant increases of pressure resistance correlate with the evidently changed wave patterns, as presented in Figure 6. In contrast, the shear component slightly increases only when the channel is very narrow (W/B < 1.3), which is because the water speed increases when the channel space is sufficiently small, thus increasing the friction associated with the boundary layer effect. Although the pressure component can have a significant increment, at a low velocity it takes a smaller proportion compared with the shear one; therefore the overall resistance increases by a smaller extent.

Table 3. Ship resistance in ice channels of varying widths (W/B), alongside breakdown into pressure and shear components and increased percentage compared with open-water resistance, obtained when

$$
\operatorname{Fr}=0.03 \text { and } h / \mathrm{T}=0.5 \text {. }
$$

\begin{tabular}{c|ccc}
\hline W/B & Total resistance & Pressure component & Shear component \\
\hline 1.1 & $0.557(+15 \%)$ & $0.149(+46 \%)$ & $0.408(+8 \%)$ \\
1.2 & $0.529(+9 \%)$ & $0.141(+38 \%)$ & $0.388(+2 \%)$ \\
1.3 & $0.519(+7 \%)$ & $0.136(+33 \%)$ & $0.383(+1 \%)$ \\
1.4 & $0.513(+6 \%)$ & $0.132(+29 \%)$ & $0.381(+0 \%)$ \\
1.6 & $0.504(+4 \%)$ & $0.123(+20 \%)$ & $0.381(+0 \%)$ \\
1.8 & $0.499(+3 \%)$ & $0.118(+15 \%)$ & $0.381(+0 \%)$ \\
2 & $0.497(+2 \%)$ & $0.116(+12 \%)$ & $0.381(+0 \%)$ \\
2.5 & $0.483(+0 \%)$ & $0.102(+0 \%)$ & $0.381(+0 \%)$ \\
3 & $0.483(+0 \%)$ & $0.102(+0 \%)$ & $0.381(+0 \%)$ \\
\hline
\end{tabular}

The influence of ice thickness on $\mathrm{R}_{\text {channel }}$ was studied by varying $h$ while keeping the other parameters constant. Figure 9 shows $R_{\text {channel }} / R_{\text {ow }}$ with different ice thicknesses non-dimensionalised by the ship draught $(h / T)$. It can be seen that as the ice thickness increases, so the ship resistance increases. This is due to the larger submerge of thicker ice reflecting deeper into the wave; also, as the ice thickness increases, there is less overwashing radiation so more surface waves are reflected, as shown in Figure 10. The results are almost the same when $h / \mathrm{T}>0.15$, suggesting that the ship-generated wave is sufficiently reflected in this range, so further increasing $h$ does not make a difference. Whereas $\mathrm{R}_{\text {channel }} / \mathrm{R}_{\text {ow }}$ is close to unity when $h / \mathrm{T}<0.05$, which means that in this range the ice is too thin to influence the ship resistance. Within the range of $0.05<h / \mathrm{T}<0.15$, the resistance increases with increasing ice thickness. In practice, the ice thickness of ice channels in Baltic Sea is usually between 0.6 1 meter (Juva \& Riska 2002), corresponding to $h / \mathrm{T}=0.06 \sim 0.1$ in this study, and yet in the Arctic the ice is usually thicker; therefore, in a real ice channel the ice will likely be thick enough to induce effective wave reflections and alter the ship resistance, and this lays in a range where the channel effect positively correlates with ice thickness. 


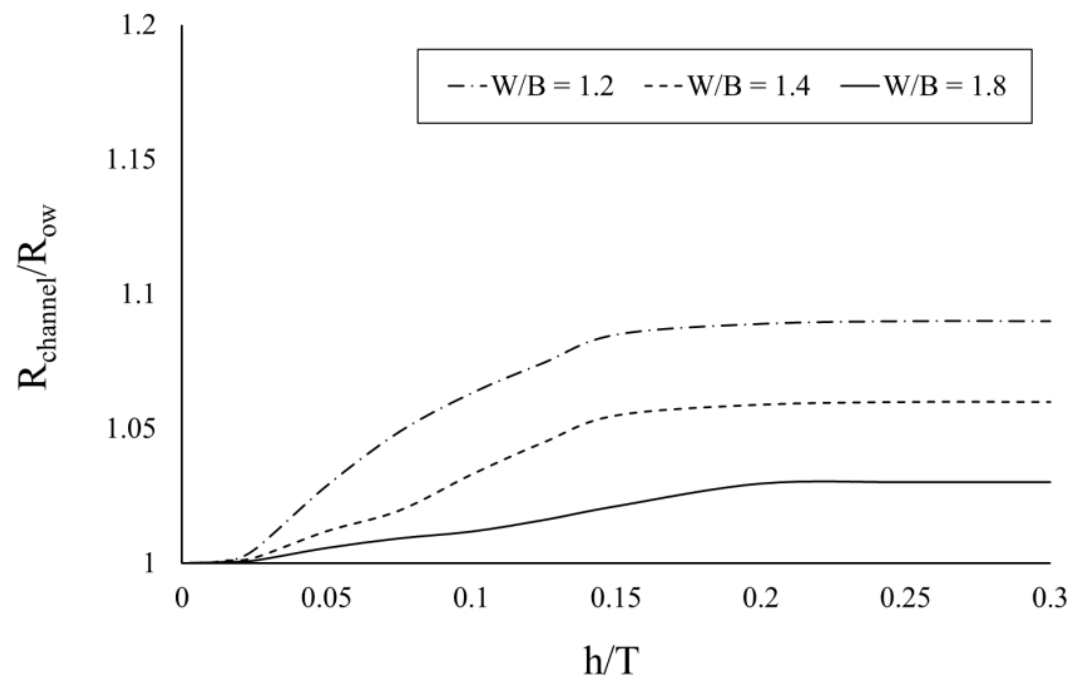

Figure 9: Ship resistance in ice channels of varying ice thicknesses, obtained when $\mathrm{Fr}=0.03$.

\section{Conclusions}

This paper studies the performance of a ship operating in an open-water ice channel, usually created by an icebreaker equipped with the ice-cleaning technology. This scenario is potentially a typical operational condition for ships escorted by icebreakers, especially of interest in future Arctic shipping, but has barely been addressed by previous research. The present work applies the CFD method to investigate the proposed problem; with the flexibility of the simulation approach, environmental parameters such as ice dimensions were subtlely varied to investigate their influences on the ship-waveice interactions. Moreover, the strong visualising capability of CFD allows the breakdown of ship resistance into pressure and shear component, as well as showing the corresponding evolvement of wave pattern. These have allowed novel insights to be obtained into the proposed problem.

Based on a series of simulations, an open-water ice channel has shown to increase the ship resistance, and the increment is mainly attributed in the pressure component, caused by changes of wave pattern due to the presence of the ice sheets. The channel effect was found evident when its width is less than 2.5 times of the ship beam and when the ice thickness is larger than $5 \%$ of the ship draught; both the effective ranges are aligned to a practical ice channel, which means the channel effect is important for such ship operations. Moreover, the channel effect was found relatively more influential when the ship is operating at a low velocity. Nevertheless, this paper is limited to a single vessel type, i.e. container ship; the channel influence could vary with other vessel types.

Noting that the nature of CFD does not solve solid mechanics, the applied method is based on the assumption that the ice sheets do not deform with the ship wake. Intended future work is to apply a fluid-structure interaction approach (Huang et al. 2019c) to include a structural solution (ice 
deformation) and couple it with the fluid solution. In addition, it would be of interest to investigate to what extent the ice channel can produce the "bank effect", where a ship tends to be sucked towards the canal wall when operating asymmetrically in a confined waterway (Vantorre et al. 2003).

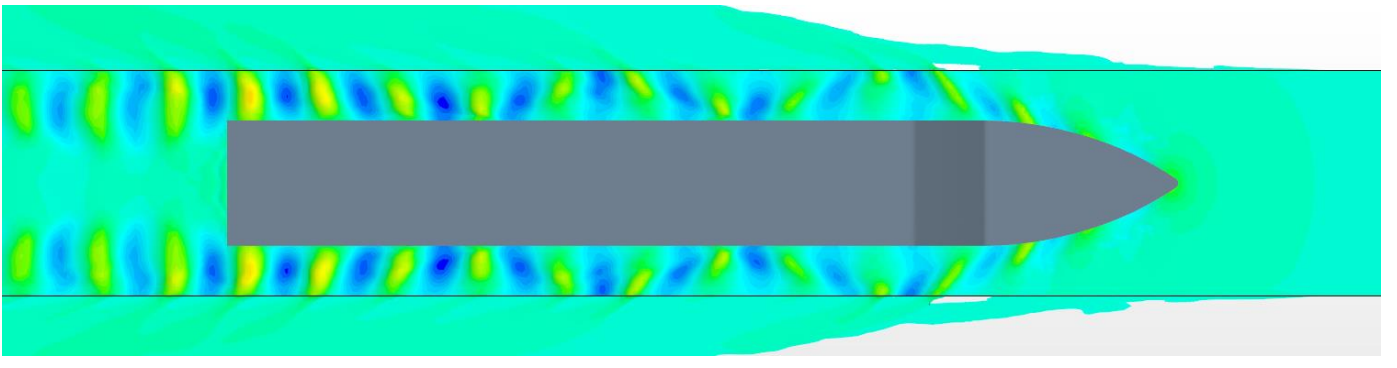

(a) $h / \mathrm{T}=0.1$, when ice is relatively thin and overwash happens

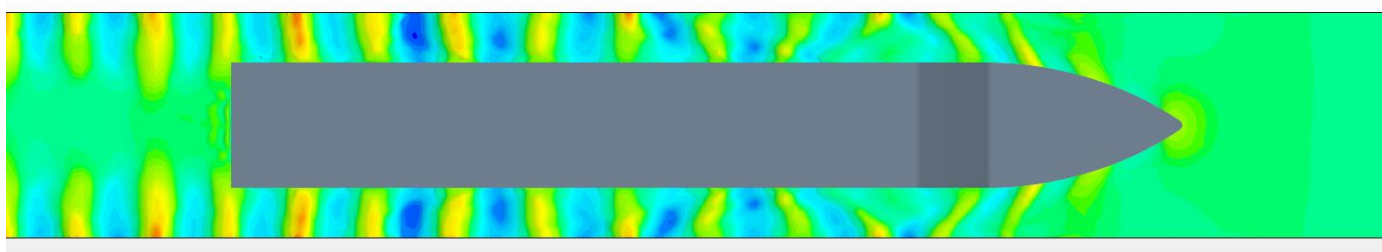

(b) $h / \mathrm{T}=0.3$, thick ice induces no overwash and wave reflection is stronger than in the above panel.

Figure 10: Wave patterns for different ice thicknesses, obtained when $\mathrm{Fr}=0.12$ and W/B $=1.8$.

\section{Acknowledgements}

This work is part of a project that has received funding from the European Union's Horizon 2020 research and innovation programme under grant agreement No 723526 - SEDNA: Safe maritime operations under extreme conditions; the Arctic case. The present paper has been facilitated by valuable suggestions from Professor Guoxiong Wu at University College London (UCL), Professor Jukka Tuhkuri at Aalto University and Mr Momchil Terziev at University of Strathclyde.The first author is grateful to Lloyds Register Foundation, UCL Faculty of Engineering Science and China Scholarship Council, for providing his PhD scholarship. The authors acknowledge the use of the UCL Grace High Performance Computing Facility (Grace@UCL), and associated support services, in the completion of this work. 
Celik IB, Ghia U, Roache PJ, Freitas CJ. 2008. Procedure for Estimation and Reporting of

351 Uncertainty Due to Discretization in CFD Applications. Journal of Fluids Engineering.

352 130(7):078001.

Gourlay TP, Ha JH, Mucha P, Uliczka K. 2015. Sinkage and trim of modern container ships in shallow water. In: Australasian Coasts \& Ports Conference 2015: 22nd Australasian Coastal and Ocean Engineering Conference and the 15th Australasian Port and Harbour Conference.: Engineers Australia and IPENZ; p. 344.

Guo C, Xie C, Zhang J, Wang S, Zhao D. 2018. Experimental Investigation of the Resistance

358 Performance and Heave and Pitch Motions of Ice-Going Container Ship Under Pack Ice Conditions.

359 China Ocean Eng. 32(2):169-178.

360 Heinonen T. 2010. Kokeellinen tutkimus nopeuden vaikutuksesta laivan jäävastukseen (Master 361 Thesis): Helsinki University of Technology.

362 Hirt CW, Nichols BD. 1981. Volume of fluid (VOF) method for the dynamics of free boundaries.

363 Journal of computational physics. 39(1):201-225.

Huang L, Li M, Igrec B, Cardiff P, Stagonas D, Thomas G. 2019. Simulation of a ship advancing in floating ice floes. In: Proceedings of the International Conference on Port and Ocean Engineering Under Arctic Conditions.

Huang L, Ren K, Li M, Tuković Ž, Cardiff P, Thomas G. 2019. Fluid-structure interaction of a large ice sheet in waves. Ocean Engineering. 182:102-111.

Huang L, Thomas G. 2019. Simulation of Wave Interaction With a Circular Ice Floe. Journal of Offshore Mechanics and Arctic Engineering. 141(4):041302.

Huang L, Tuhkuri J, Igrec B, Li M, Stagonas D, Toffoli A, Cardiff P, Thomas G. 2019. Ship resistance when operating in floating ice floes: a combined CFD\&DEM approach. arXiv preprint arXiv:190910018.

ITTC. 2017. Uncertainty Analysis in CFD Verification and Validation Methodology and Procedures. Recommended Procedures and Guidelines.

Jeong S-Y, Jang J, Kang K-J, Kim H-S. 2017. Implementation of ship performance test in brash ice channel. Ocean Engineering. 140:57-65.

378 Juva M, Riska K. 2002. On the power requirement in the Finnish-Swedish ice class rules. Winter 379 navigation Research Board, Res Rpt. 53.

380 Kim WJ, Van SH, Kim DH. 2001. Measurement of flows around modern commercial ship models. Experiments in fluids. 31(5):567-578. and Technology. 10(3):219-234. 
Konno A, Saitoh O, Watanabe Y. 2011. Numerical investigation of effect of channel condition against ships resistance in brash ice channels. In: Proceedings of the International Conference on Port and Ocean Engineering Under Arctic Conditions.

Koskinen P, Savikurki J. 1993. A propulsion system based on azimuth thrusters and its possibilities in icebreaking technology. In: Proceedings of the International Conference on Port and Ocean Engineering Under Arctic Conditions.

Laxon SW, Giles KA, Ridout AL, Wingham DJ, Willatt R, Cullen R, Kwok R, Schweiger A, Zhang J, Haas C. 2013. CryoSat-2 estimates of Arctic sea ice thickness and volume. Geophysical Research Letters. 40(4):732-737.

Leiviskä T, Tuhkuri J, Riska K. 2001. Model Test on Resistance in Ice-free Ice Channels. In: Proceedings of the International Conference on Port and Ocean Engineering Under Arctic Conditions.

Melia N, Haines K, Hawkins E. 2017. Future of the Sea: Implications from opening Arctic sea routes. Foresight-Future of the Sea Evidence Review London: Government Office of Science.

Menter F. 1993. Zonal two equation kw turbulence models for aerodynamic flows. In: 23rd fluid dynamics, plasmadynamics, and lasers conference.

Mucha P. 2019. Fully-Coupled CFD-DEM for Simulations of Ships Advancing Through Brash Ice. In: SNAME Maritime Convention: The Society of Naval Architects and Marine Engineers.

Mucha P, Deng G, Gourlay T, Moctar E, Ould B. 2016. Validation studies on numerical prediction of ship squat and resistance in shallow water. In: 4th MASHCON-International Conference on Ship Manoeuvring in Shallow and Confined Water with Special Focus on Ship Bottom Interaction.

Mucha P, el Moctar O. 2014. Numerical Prediction of Resistance and Squat for a Containership in Shallow Water. In: Proceedings of the 17th Numerical Towing Tank Symposium.

Mucha P, el Moctar O, Dettmann T, Tenzer M. 2018. An experimental study on the effect of confined water on resistance and propulsion of an inland waterway ship. Ocean Engineering. 167:11-22.

Phillips TS, Roy CJ. 2016. A new extrapolation-based uncertainty estimator for computational fluid dynamics. Journal of Verification, Validation and Uncertainty Quantification. 1(4):041006.

Skene DM, Bennetts LG, Meylan MH, Toffoli A. 2015. Modelling water wave overwash of a thin floating plate. Journal of Fluid Mechanics. 777.

Smith LC, Stephenson SR. 2013. New Trans-Arctic shipping routes navigable by midcentury. In: Proceedings of the National Academy of Sciences. Vol. 110(13). [place unknown]; p. E1191-E1195.

Stroeve JC, Kattsov V, Barrett A, Serreze M, Pavlova T, Holland M, Meier WN. 2012. Trends in Arctic sea ice extent from CMIP5, CMIP3 and observations. Geophysical Research Letters 39(16).

Terziev M, Tezdogan T, Oguz E, Gourlay T, Demirel YK, Incecik A. 2018. Numerical investigation of the behaviour and performance of ships advancing through restricted shallow waters. Journal of Fluids and Structures. 76:185-215.

Tezdogan T, Incecik A, Turan O. 2016. A numerical investigation of the squat and resistance of ships advancing through a canal using CFD. Journal of Marine Science and Technology. 21(1):86-101.

Vantorre M, Delefortrie G, Eloot K, Laforce E. 2003. Experimental investigation of ship-bank interaction forces. In: International Conference MARSIM. 
426 Versteeg HK, Malalasekera W. 2007. An introduction to computational fluid dynamics: the finite 427 volume method. Pearson Education.

428 Wadhams P. 2017. A farewell to ice: a report from the Arctic. Oxford University Press.

429 Zhang Z, Liu H, Zhu S, Zhao F. 2006. Application of CFD in ship engineering design practice and 430 ship hydrodynamics. Journal of Hydrodynamics. 18(1):308-315.

431 